\title{
Psychological-pedagogical problems and prospects of distance learning of students during the Covid-19 pandemics
}

\author{
George Abuselidze ${ }^{1, *}$, Inna Radzivilova ${ }^{2}$, and Olga Mohylevska ${ }^{2}$ \\ ${ }^{1}$ Batumi Shota Rustaveli State University, 6010, Batumi, Georgia \\ ${ }^{2}$ Kyiv International University, 03041, Kiev, Ukraine
}

\begin{abstract}
The article analyses the psychological and pedagogical problems and prospects of the distance learning of students during the pandemic period. Studies have shown that the learning process during the quarantine in the spring of 2020 was stressful for all participants in the educational process. This was caused by the lack of previous experience of distance learning and the response from the government and the number of educational problems. It is proved that the problem of insufficient universal access to the internet and the equipment necessary for training has affected both teachers and students. The current situation shows that some teachers working at higher education institutions replaced remote classes with the form of written works, which led to excessive workload of students. Such methods do not contribute to the quality of material assimilation, but on the contrary, create additional stress. It is proved that computerization affects all spheres of human activity and is an important factor in changing the quality of society life. The authors note that in order to ensure the development of higher distance education, it is necessary to improve the regulatory framework in the field of higher distance education, create a computer infrastructure, prepare software for the introduction of electronic educational platforms, as well as train and retrain teachers for conducting distance education courses. It is noted that during the process remote technologies, teachers use various forms of work with students. In particular, including Zoom classes, Skype classes, web classes, where students independently study an educational resource, perform tasks and the teacher checks it and gives a mandatory review of the completed task. The algorithm for assessing the quality of distance learning systems is justified and the use of an integral indicator with weighting coefficients is proposed, which allows us to quantify the value of local quality indicators and complex quality characteristics of distance learning systems.
\end{abstract}

\section{Introduction}

The pandemic has led to significant changes in the field of education, and it has caused educational problems. At the beginning of the quarantine in the spring of 2020, all educational institutions switched to distance learning. The pandemic has led to significant

\footnotetext{
*Corresponding author: george.abuselidze@gmail.com
} 
changes in education throughout the world in 2020. The vast majority of countries have closed all educational institutions for at least some time, and at the end of the training stopped in some areas. According to UNESCO, as of April 2020, all schools were closed in 191 countries, where more than $90 \%$ of all students in the world live. The UN's fourth Sustainable Development Goal, 2030, calls for "ensuring comprehensive and equitable quality education and promoting lifelong learning opportunities for all".

The level of education directly affects the income and employment of the population better educated people find jobs easier, have better working conditions and earn more. In addition, it is positively associated with life expectancy, health, and social integration. Better educated people are more involved in public and political life, they are actively involved in the development of a truly democratic society.

The learning process during the quarantine in the spring of 2020 was stressful for all participants of the educational process. Due to the lack or lack of previous experience of distance learning and the response from the government, a number of educational problems have emerged [1]. It should be noted that all these surveys were conducted in the spring, and therefore show the problems faced by participants in the educational process during the period of strict quarantine, when all institutions were on distance learning. However, most of these problems are still relevant and unresolved.

The aim of the research is to study the psychological and pedagogical problems and prospects of distance learning of students during the quarantine period and to develop methods, tools and new models for ensuring the quality of such systems for distance learning.

\section{Research methods}

\subsection{Literature review}

The analysis of the scientific psychological and pedagogical literature that has appeared recently shows significant attention to the problems of implementing distance technologies in the educational process in higher education institutions. The scientific and pedagogical foundations of distance learning were developed by scientists: V. Kukharenko, S. K. Pande, V. Chumak, C. Babaoglu, M. K. Oktem, A. Manzoor, V. P. Ignatiev, E. A. Arhangelskaja, A. Tella, O.M.A. Albakri, A. Albakri, E. Kesim, S. K. Prasad, etc [2-15].

Many well-known national scientists work in the field of theory and practice of distance learning. The works of such scientists as J. Nyoni, C. E. Beck, G. R. Schornack, B. Holmberg, etc. deserve special attention. It was found out that the issues of scientific support of distance learning, its problems and directions of study were reflected in the studies of H. Kang, A. S. Gyorke, A. Mukoviz, A. Piu, and others. Certain aspects of continuing education and open learning, organizational and pedagogical foundations of distance training of specialists are reflected in the works of M. Aslam, J. Cadorath, S. Harris, F. Encinas, J. Bidarra, E. Rusman, A. O. Bubin, S. I. Boiarchuk, A. M. Tsypliuk, S. Bell, etc [16-27].

At the same time, despite the existence of diverse and fairly large-scale research on distance education, today there are practically no scientific works that would holistically and comprehensively address the problem of distance learning of students during the quarantine period.

Unfortunately, Ukraine and Georgia have not yet conducted fundamental research on how distance learning takes place in higher education institutions. However, it can be assumed that teachers also face the problem of lack of experience and skills of distance learning, organizing work independently. At the same time, there is a lack of 
recommendations for the organization of classes in the context of distance learning, as well as tools with which teachers could share their experience with each other.

\subsection{Research instruments}

In the course of the research, we used a set of complementary methods, namely, the analysis and synthesis of scientific and pedagogical material, which contributed to the concretization of the essence of distance education and distance learning, generalization and systematization of theoretical data.

\section{Results and discussion}

Since March 2020, when the epidemic began and the first cases of COVID-19 were confirmed, all educational institutions have been closed to visitors. In accordance with the Resolution of the Cabinet of Ministers (CMU) No. 211 of March 11, 2020, quarantine was introduced throughout the country, and education applicants were banned from attending educational institutions at all levels. The responsibility to decide whether an educational institution is switching to distance learning was assigned to the local authorities in accordance with the government's decision on the definition of epidemiological zones.

In communities where the incidence rate is low - in the green zone - education took place in educational institutions almost unchanged. The necessary condition was to comply with the general sanitary recommendations for disinfection, airing the premises, washing hands, as well as organizing training to prevent crowding. Among the recommendations asynchronous schedule, the use of various entrances to the premises of the educational institution, the use of masks at recess.

According to the general requirements of adaptive quarantine, in the event of a change in the status to "yellow" or "orange", the organization of the educational process in general secondary education institutions did not change. However, local authorities could provide additional advice on the safe organization of training in the event of an increase in the incidence rate.

You can see a certain difference between the government's decisions in the spring and autumn. During the strict quarantine, when the number of patients in the country was officially lower, all educational institutions were transferred to distance learning, and only by the beginning of the summer gradually opened some of them to the public. In the autumn, when the number of patients began to grow faster, the government tried to avoid distance learning in schools and closing kindergartens.

The marriage of universal Internet access and the equipment needed for training. This problem affected both teachers and students. According to statistics, $62.35 \%$ of principals noted that most teachers and students did not have the necessary equipment at home, and $46.9 \%$ indicated a low-speed Internet connection. Most of the teachers used a computer together with other family members, and $6 \%$ of the teachers did not have access to highspeed Internet. The low quality of the Internet connection is indicated by $22.3 \%$ of the parents surveyed. In addition, $8.8 \%$ of parents said that their families do not have a computer. According to a survey conducted by the Education Ombudsman, the majority of children $(81.6 \%)$ used mobile phones, probably smartphones, for distance learning. But fewer people use a laptop (45.6\%) and a desktop computer (34.3\%). However, not all tasks can be performed on the phone, so students could require laptops or computers that belonged to their parents. If the parents also worked remotely, this could complicate both learning and work.

In institutions of higher education: some teachers replaced remote classes with working out in the form of written works, which led to excessive workload of students. Such 
methods do not contribute to the qualitative assimilation of the material, but, on the contrary, create additional stress. Moreover, the situation within the same university could be different, since some teachers gave written tests, while others conducted remote classes. At the same time, there could be no coordination between the teachers themselves and their control over the load on the students. This problem is being re-actualized now, because most higher education institutions have switched to distance learning in 2021. As a result, we get a new impetus to the development of computer technology, telecommunications and the Internet to provide distance learning. Distance education courses allow you to fully use modern means of transmitting educational information and managing the educational process; it is almost twice as cheap as traditional forms of organizing the educational process. The training tools created on the basis of modern information carriers in combination with new technological solutions, as well as modern methodological support, allow you to independently master the methods of educational activity create conditions for the independent assimilation of students' disciplines within the distance education system. In modern conditions of modernization of the education system, an increasing role is given to the methods of active cognition, self-education and distance learning.

Distance learning is a relatively new form of learning and a field of scientific research. Distance courses are a process of learning and teaching disciplines using electronic technologies, provides flexible access to learning resources, experts, colleagues, educational services and services, and reveals the potential of computer technology in the ability to make learning accessible at any time and in any place. So, distance learning is an educational process organized on certain topics of academic disciplines, providing for an active exchange of information between students and the teacher, as well as between students themselves, using to the maximum extent modern means of information technology (audio-visual means, personal computers and telecommunications).

Computerization affects all spheres of human activity and is an important factor in changing the quality of life of society. The emergence of new information technologies also affects the culture. As E.Z. Vlasova et al., and S. Sysoeva notes, the minimum level of culture in the past provided only for mandatory reading and writing skills, and now the present requires mandatory skills in reading and creating hypertext documents $[28,29]$. This leads to the formation of an information culture that encompasses the totality of all values in the information sphere created by humanity during various stages of historical development.

A person with a developed information culture is characterized as a person with a certain set of knowledge and skills, including: possession of information resources, information worldview, information environment and information behavior, the ability to correctly formulate their information needs and requests, the ability to effectively and quickly carry out an independent search for information using both traditional and nontraditional methods. First of all, computer search engines: the ability to efficiently store and quickly process large flows and arrays of information; knowledge of the norms and rules of "information ethics" and the ability to conduct information and communication dialogue. An important role in the formation of an information culture is played by education, and especially by education aimed at educating specialists of the information society, producing in them the appropriate skills and abilities: differentiation of information, allocation of significant information, development of criteria for its evaluation, preparation of information and its use.

At the present stage of modernization and development of education, computerization and individualization of teaching tools, the creation of intelligent didactic systems that contribute to improving the effectiveness of the educational process is a priority.

Information technologies of distance learning are technologies for creating, transmitting and storing educational materials, organizing and supporting the educational process of 
distance learning using telecommunications [30]. Distance learning technologies - a set of educational technologies, including psychological and pedagogical and information and communication technologies, that provide an opportunity to implement the process of distance learning in educational institutions and scientific institutions. Based on our research, we have identified two main technologies for presenting information in distance learning: synchronous and asynchronous [31] (Table 1).

Table 1. Common synchronous and asynchronous technologies in distance learning (Source: Compiled by the authors on the basis of a summary of research).

\begin{tabular}{|c|c|c|}
\hline & Synchronous & Asynchronous \\
\hline Video & video conferences & Video material, TV show \\
\hline Audio & audio conferences & Audio material, radio program \\
\hline Information & $\begin{array}{c}\text { Computer video conference, Internet } \\
\text { chat }\end{array}$ & $\begin{array}{c}\text { Web-page, e-mail, CD-ROM with } \\
\text { educational material, textbook, study guide }\end{array}$ \\
\hline
\end{tabular}

So it can be noted that distance learning technologies are a set of educational pedagogical and information and communication technologies, methods, forms and means, the purpose of which is to obtain a high level of training when using distance courses and implementing distance learning in educational institutions.

The introduction of distance learning technologies in the educational process is aimed at a deeper understanding of the educational material; the formation of such competencies as: communicative (direct communication using the means of the network), informational (search for information from different sources and the possibility of its critical reflection), self-education (the ability to learn independently).

When using distance learning in a higher education institution, the role of the teacher changes. It is responsible for such functions as coordinating the cognitive process, correcting the course being studied, advising students during the improvement of the individual curriculum, managing their educational projects, etc. It helps students in their professional self-determination.

The student's activity changes from gaining knowledge to finding it. In the case of distance learning, a tutor assigned to a group of students combines the qualities of a teacher, a consultant and a manager of the educational process. The tutor becomes a key figure in distance learning.

For high-quality implementation of distance education projects on the basis of higher educational institutions, the following areas of work are necessary:

* Improving the methodology of training specialists. For example, distance learning allows you to study simultaneously in two languages, which is especially important for people who are abroad, because in some cases, the lack of the necessary level of knowledge of the language leads to a decrease in their competitive ability. This is also important for specialists working in export-oriented industries, where the creation of equipment requires the participation of foreign specialists or operation is associated with traveling abroad. One of the areas of improvement is the creation of various mixed forms of training, taking into account the need to acquire skills in working with equipment, the need for communication between various specialists, students and teachers. To maintain communication in groups of students and implement the group method of teaching, demonstration videos, educational films, webinars of various levels are widely used as methods of distance learning, in order not only to improve the knowledge and skills of users, but also to constantly expand the audience of specialists, students who can become users of the system. The main purpose of these methods is to get feedback from the audience.

* Modification and development of courses and individual modules on design and software for embedded systems based on specialized programming systems. 
* Introduction of virtual and remote laboratories with Internet access into the practice of the educational process.

* Development of teaching methods, training of teachers and researchers, master classes on the use of remote laboratories.

* The formation and training of groups of students should take place with constant monitoring and evaluation of the results.

* The formation and training of groups of students should take place with constant monitoring and evaluation of the results.

* Conducting seminars for employees of enterprises and organizations in the region to attract specialists to constantly improve the level of education.

Based on the above, it is possible to build an appropriate quality model for software systems taking into account the specifics of the application area, since its characteristics reflect the general needs of users and customers in information resources, and the corresponding attributes and metrics allow us to express the quantitative and qualitative degree of their satisfaction (Figure 1).

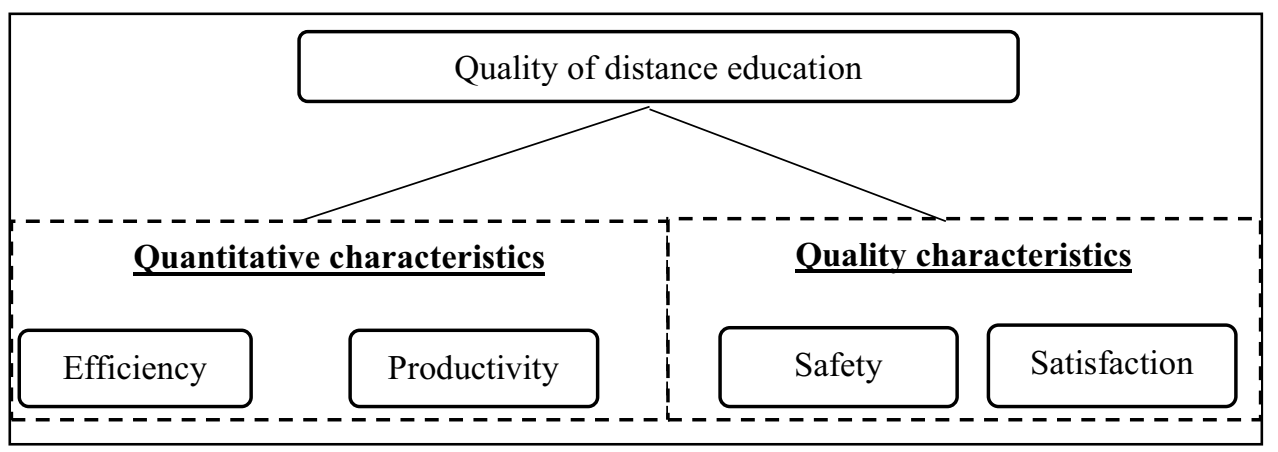

Fig. 1. The structure of the model of the quality of distance education in the process of use (Source: compiled by the authors on the basis of generalization).

To determine the quality of distance learning systems, we propose to consider the evaluation process in the context of design and implementation. The design process, as a component of the overall quality assessment process, is its theoretical basis and includes the construction of a specification of quality requirements, the selection of metrics and the definition of evaluation criteria, as well as the construction of a model for combining elementary criteria. Figure 2 shows the design process with its stages, main input, intermediate, and output data. The stage of determining the quality requirements reflects the needs of the target audience, takes into account the criteria of the basic quality model and the evaluation goals. Therefore, the features of the subject environment, characteristics, sub characteristics of the quality model, and the needs of the target user should be reflected in the quality requirements tree. 


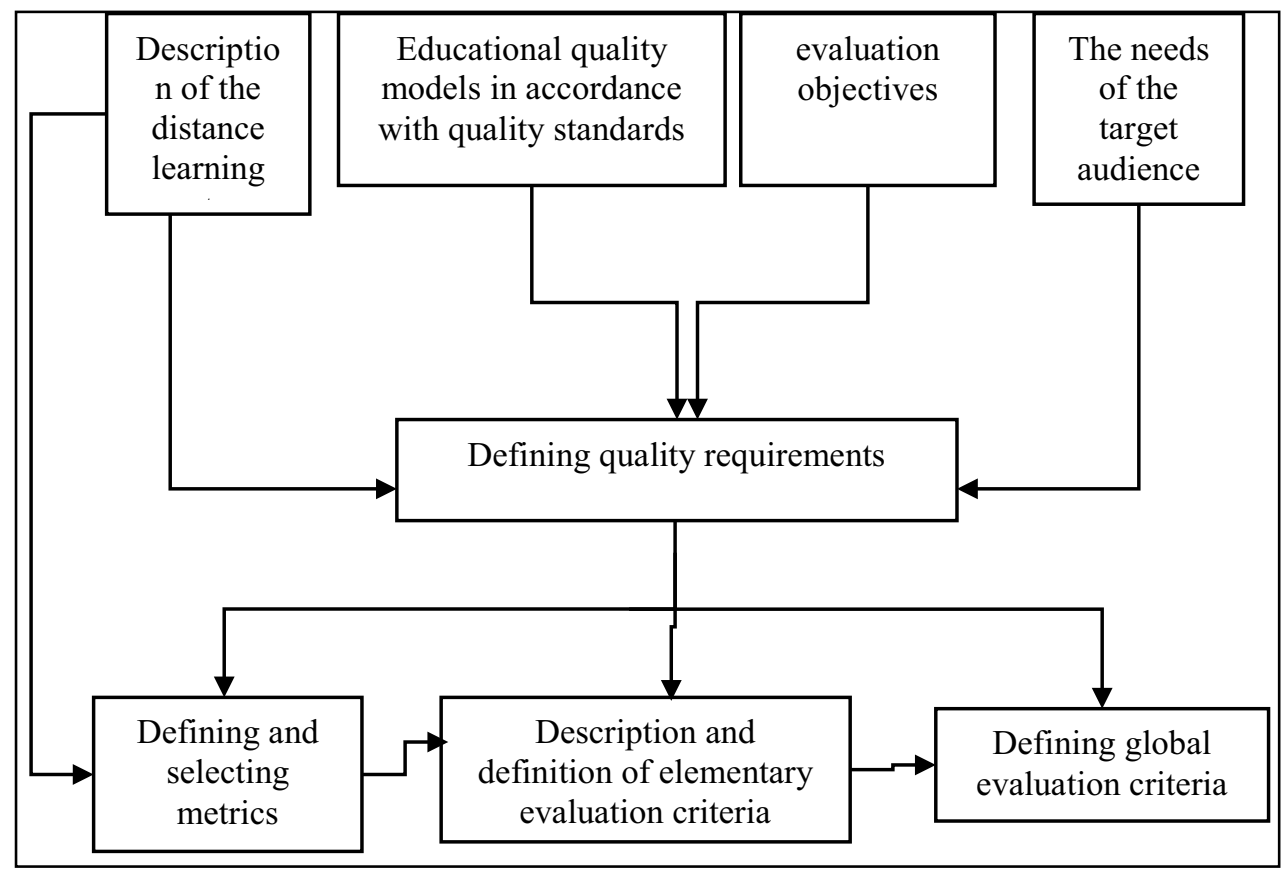

Fig. 2. The process of designing a distance learning system as a component of the quality assessment process. Source: Compiled by the authors on the basis of the conducted research.

For the designed quality requirements, you need to set attributes and metrics and match the basic evaluation criteria. A set of elementary criteria that characterize the same entity is made up of private or global quality criteria. Based on the given representation of the design process, quality models are obtained, on the basis of which the process of implementing quality assessment is carried out. The process of implementing the quality assessment of distance learning systems consists of three phases: measurement of implementation indicators, elementary assessment, and partial or general assessment. The quality indicators of distance learning systems are measured based on the attributes defined in the design process. Methods and methods for measuring the values of indicators can be carried out automatically or obtained manually. This depends on the type of attribute, the metric, and the available resources that the quality assessors have.

The models used in assessing the quality of remote control systems, in particular based on recommendations, can be divided into two categories. The first category includes models based on linear additive models, and the second category includes those that use nonlinear multi-criteria models. When used as both models, the importance of quality indicators will depend on the weight factors. Assume that the integrated quality assessment procedure uses a linear additive model. Then you can determine the private or general quality of distance learning systems using an integral indicator. The integral quality indicator is calculated by the formula:

$$
Q=\sum_{i=1}^{N} q_{i}(X) \times k_{i}
$$

Where:

Q - integral estimation;

$\mathrm{K}_{\mathrm{i}}$ - weight ratio;

$\mathrm{N}$ - number of attributes. 
So, the integral assessment of the quality of distance learning systems is the sum of the partial quality indicators of individual quality attributes defined in the quality models, multiplied by the weight coefficients of the attributes, respectively. The weighting factor $\mathrm{k}$ is a coefficient that indicates the importance of a particular attribute in the constructed quality model, depending on the application area. The ranking of the weight of attributes for a specific subject area is carried out by determining the weight coefficient. In order to reduce the influence of subjective factors and provide a set of optimal solutions for determining the weight coefficients, it is proposed to use the method of pairwise comparisons. This method allows you to choose alternative solutions for a variety of options and is able to provide the level of quality that the customer requires. The essence of the method of pairwise comparisons is based on the construction of matrices of pairwise comparisons of attributes and the establishment of expert coefficients of the relationship between attributes.

\section{Conclusions}

Consequently, the organization of distance learning has become a big challenge for most teachers. Some of them had some experience in this matter or were quickly able to master the necessary skills. However, teachers require systematic assistance in working with modern technologies. The quarantine only raised this issue once again, but this problem should be solved independently of the quarantine. After all, the world is moving forward and teachers must have the appropriate skills and support to move along with it. A necessary condition for this should be the presence in each school of a sufficient number of computers and other educational equipment for the work of teachers, as well as the Internet available to all.

Using remote technologies, teachers use various forms of work with students, including Skype classes, web classes, where students independently study an educational resource, perform tasks, and the teacher checks it and gives a mandatory review of the completed task. Students are constantly in an active role. The forms of teaching of each class correspond to the peculiarities of students ' perception and mental activity, the goals and objectives of specific topics. The algorithm for assessing the quality of distance learning systems is justified and the use of an integral indicator with weighting coefficients is proposed, which allows us to quantify the value of local quality indicators and complex quality characteristics of distance learning systems.

The modern level of organization and implementation of distance learning in mathematics can be provided by: using the latest network technologies; ensuring access of all participants of the educational process to computers and broadband computer networks; using modern instrumental systems for the organization of distance learning; the use of modern forms and methods of teaching based on the active independent work of students; the use of interactive, multimedia electronic means for educational purposes; the organization of special training of teachers in the field of creating and using distance learning courses in mathematics using instrumental software systems.

\section{References}

1. G. Abuselidze, A. Slobodianyk, E3S Web of Conferences 210, 15016 (2020) doi:10.1051/e3sconf/202021015016

2. V. Kukharenko, Methods of Contents Curator. Information Technologies in Education 16, 100-107 (2013) doi:10.14308/ite000433 
3. S.K. Pande, Advances in Educational Technologies and Instructional Design, 71-95 (2018) doi:10.4018/978-1-5225-2624-7.ch004

4. V. Humak, Technologies of Intellect Development 4(1), (2020). doi: $10.31108 / 3.2020 .4 .1 .1$

5. C. Babaoglu, M.K. Oktem, Advances in Educational Technologies and Instructional Design, 1-17 (2018) doi:10.4018/978-1-5225-2624-7.ch001

6. A. Manzoor, Advances in Educational Technologies and Instructional Design, 18-39 (2018) doi:10.4018/978-1-5225-2624-7.ch002

7. V. P. Ignatiev, E. A. Arhangelskaja, Problems of Modern Education 6, 148-160 (2020) doi:10.31862/2218-8711-2020-6-148-160

8. A. Tella, Encyclopedia of Education and Information Technologies, 1-10 (2020) doi:10.1007/978-3-319-60013-0_260-1

9. O. M. A. Albakri, A. Albakri, Advances in Educational Technologies and Instructional Design, 150-164 (2021) doi:10.4018/978-1-7998-4846-2.ch011

10. E. Kesim, Educational Leadership and Administration, 1741-1757 (2017) doi:10.4018/978-1-5225-1624-8.ch079

11. S.K. Prasad, Advances in Educational Technologies and Instructional Design, 119-152 (2018) doi:10.4018/978-1-5225-2624-7.ch006

12. G. Abuselidze, L. Beridze, SHS Web of Conferences 66, 01001 (2019) doi:10.1051/shsconf/20196601001

13. G. Abuselidze, Proceedings of 5th International Conference on Lifelong Education and Leadership for All (ICLEL 2019), 243-251 (2019)

14. G. Abuselidze, L. Davitadze, E3S Web of Conferences 224, 03015 (2020). doi:10.1051/e3sconf/202022403015

15. G. Abuselidze, L. Mamaladze, Journal of Physics: Conference Series 1840(1), 012040 (2021) doi:10.1088/1742-6596/1840/1/012040

16. J. Nyoni, Mediterranean Journal of Social Sciences 4(14), 735-744 (2013) doi:10.5901/mjss.2013.v4n14p735

17. C.E. Beck, G.R. Schornack, Theory and Practice for Distance Education. Distance Learning and University Effectiveness, 119-143 (2004) doi:10.4018/978-1-59140-178$0 . \operatorname{ch} 006$

18. Theory and Practice in Distance Education. Learner-Centered Theory and Practice in Distance Education (2003) doi:10.4324/9781410609489-8

19. B. Holmberg, Theory and Practice of Distance Education (Routledge, 2005) doi:10.4324/9780203973820

20. H. Kang, A.S. Gyorke, Open Learning: The Journal of Open, Distance and e-Learning 23(3), 203-214 (2008) doi:10.1080/02680510802420050

21. A. Piu, Simulation, Online and Distance Learning, 346-356 (2008) doi:10.4018/978-159904-935-9.ch033

22. M. Aslam, Open Learning: The Journal of Open, Distance and e-Learning 15(3), 309315 (2000) doi:10.1080/713688405

23. J. Cadorath, S. Harris, F. Encinas, Open Learning: The Journal of Open, Distance and e-Learning 17(2), 139-152 (2002) doi:10.1080/02680510220146904

24. J. Bidarra, E. Rusman, Open Learning: The Journal of Open, Distance and e-Learning 32(1), 6-20 (2016). doi:10.1080/02680513.2016.1265442 
25. A.O. Bubin, S.I. Boiarchuk, A.M. Tsypliuk, Pedagogical Sciences Reality and Perspectives 78, 35-38 (2020). doi:10.31392/npu-nc.series5.2020.78.07

26. S. Bell, Sustainable distance learning for a sustainable world. Open Learning: The Journal of Open, Distance and e-Learning 31(1), 1-8 (2016). doi:10.1080/02680513.2016.1164506

27. I. Dimitrov, A. Dimitrova, N. Davydenko, III International Conference on High Technology for Sustainable Development (HiTech), 1-4 (2020). doi:10.1109/HiTech51434.2020.9363984

28. E.Z. Vlasova, S.V. Goncharova, V.P. Barakhsanov, E.A. Ivanova, N.A. Karpova, T.S. Iljina, A.S. Sysoeva, Dilemas contemporáneos: Educación, Política y Valores 7(S10), 52-52 (2019)

29. S. Sysoeva, The Advanced Science Journal 2015(4), 82-88 (2015) doi:10.15550/asj.2015.04.082

30. K. Passerini, M.J. Granger, Computers \& Education 34(1), 1-15 (2000) doi:10.1016/S0360-1315(99)00024-X

31. N.L. Ramo, E.S. Hald, A. Huang-Saad, Biomedical engineering education 1(1), 61-66 (2021) doi:10.1007/s43683-020-00009-w 